\title{
La gobernanza organizacional en las instituciones de educación superior
}

\author{
Working Paper No. 10
}

\author{
Norhys Torregrosa Jiménez ${ }^{1}$ \\ Luisa Fernanda Moreno Munevar ${ }^{2}$ \\ Dalia Carreño Dueñas ${ }^{3}$ \\ Manuel Fernando Moya ${ }^{4}$ \\ Carlos Alberto Piñeros Cortes ${ }^{5}$
}

\section{Resumen}

La gobernanza organizacional hace referencia a los lineamientos o métodos bajo los cuales se desenvuelve el comportamiento y posterior gestión de quienes dirigen la organización; los mecanismos utilizados para establecer las relaciones con sus partes interesadas o grupos de interés internos y externos, en donde cada decisión que tomen ellos, o que la organización tome sobre ellos, definirá roles, influencias, otorgará poderes y generará afectación a las partes involucradas lo que terminará por facilitar o no el cumplimiento de objetivos organizacionales.

\section{Palabras clave}

Gobernanza, métodos, gestión, educación, organización, estrategia

\footnotetext{
${ }^{1}$ Doctora en derecho Universidad Externado de Colombia, Bogotá Magister en docencia universitaria de la Salle, Bogotá. Magister en Ciencia Política Pontificia Universidad Javeriana, Bogotá. Directora del Centro de investigación Facultad de derecho Usta. Integrante del grupo de Investigación Socio Humanista del Derecho, correo dir.ciderecho@usantotomas.edu.co

Cvlac http://scienti.colciencias.gov.co:8081/cvlac/visualizador/generarCurriculoCv.do?cod_rh=0000389820 Orcid https://orcid.org/0000-0003-1445-2166

Google académico https://scholar.google.es/scholar?hl=es\&as_sdt=0\%2C5\&q=Norhy+Esther+Torregrosa+Jim\%C3\%A9nez\&btn $\mathrm{G}=$

${ }^{2}$ Joven investigadora. MBA.Universidad Santo Tomás. https://scienti.minciencias.gov.co/cvlac/visualizador/generarCurriculoCv.do?cod_rh=0001783875

${ }^{3}$ Licenciada en Filosofía y Letras, Licenciada en Filosofía y Ciencias Religiosas, Abogada, Especialista en Derecho Penal, Magister en Educación, Doctora en Derecho Universidad Santo Tomás, doctoranda en Derecho Universidad de Buenos Aires. Docente Universidad Santo Tomás, Investigador Asociado. daliacarreno@usantotomas.edu.co. https://scienti.minciencias.gov.co/cvlac/visualizador/generarCurriculoCv.do?cod rh=0000518409, https://orcid.org/0000-0002-9693-8436, https://scholar.google.com/citations?user=AIS6hbUAAAAJ\&hl=es

${ }^{4}$ Abogado, Doctor en sociología jurídica e instituciones políticas, Posdoctorante en derecho tesis de grado en Semiótica Penal, Investigador en semiótica jurídica, Ha sido conjuez de la Sala Penal de Casación de la Corte Suprema de Justicia.

http://scienti.colciencias.gov.co:8081/cvlac/visualizador/generarCurriculoCv.do?cod_rh=0000510955. https://orcid.org/0000-0003-4969-9310, https://scholar.google.com/citations?user=zSRmc98AAAAJ\&hl=es.

${ }^{5}$ Magister en Filosofía, especialista en psicología jurídica, psicólogo Universidad Nacional, Director Escuela de Metapsicología.
} 


\section{Introducción}

Entendiendo a las Instituciones de Educación Superior (IES) como organizaciones, el concepto de gobernanza les es totalmente aplicable. Sin embargo, es importante aclarar que, de acuerdo con la clasificación según su naturaleza jurídica, (IES privadas e IES públicas) se determina el nivel de autonomía que se tiene para ejercer la gobernanza.

Los principales grupos de interés en toda organización son los clientes, los proveedores, los empleados, los accionistas, el gobierno y la sociedad en general. Todos tienen necesidades específicas y sobre ellas basan sus exigencias a la organización.

\section{Un modelo organizacional para las IES}

Para el caso de las IES, la mayor de las exigencias que le hacen sus partes interesadas es la calidad de la educación que brinda y para ello quien planee, diseñe y ejecute el sistema de educación que va a utilizar debe asumir un compromiso de formación permanente, mejora y actualización continua. En un mundo globalizado como el actual, la competencia es visible en todos los sectores de la economía mundial y el sector universitario no es la excepción. La IES debe contar con una estrategia diferenciadora marcada en el conocimiento, que le permita crear su propia identidad y con base en ésta, diseñar su modelo organizacional el cual debe ser aceptado y legitimado por sus partes interesadas.

Es importante aclarar que el concepto gobernanza difiere de a lo que hace referencia el termino gobierno. Trayéndolo al caso de las IES, el gobierno universitario es en la estructura organizacional el órgano superior de la institución y la gobernabilidad es la manera en la que se gestiona y administra la misma. En ocasiones, el gobierno universitario delega parte de su poder para tomar de decisiones (gobernanza) en personal que considera capacitado para ello, y es entonces, sobre éste delgado que cae el compromiso de ejercer una gobernanza responsable con el propósito siempre de fortalecer la academia.

El tamaño de la IES es proporcional al nivel de complejidad que hay en administrarla, de ahí, que la técnica para gestionar administrativamente cualquier organización, resulta ser un factor clave en el éxito o fracaso de esta.

La gobernanza surge en el mismo momento en el que se crea la institución, al tener claro los objetivos que se quieren alcanzar, el enfoque debe direccionarse siempre en aumentar los niveles de eficiencia, eficacia y efectividad para lograrlos. Anteriormente, se practicaba de forma empírica, pero con los avances sociales, económicos, políticos, tecnológicos y demás, se ha venido perfeccionando conforme se ha reconocido su importancia. En relación con lo anteriormente expuesto, se hace relevante mencionar que quien ejerza la gobernanza lo debe hacer por periodos razonables, pues es contraproducente otorgar poder por mucho tiempo y además, se debe dar paso al cambio al interior de la institución también.

La gobernanza debe ser el resultado de la participación activa de las partes interesadas con la institución, y, es que, al estar relacionada su actividad principal con la transferencia y 
generación de conocimiento, el compromiso cobra mayor importancia. Una gobernanza que es ajena a las necesidades de sus grupos de interés es potencialmente una amenaza y por ello se hace necesario la actualización de la normatividad que actualmente regula la gestión de las IES.

Los estudiantes de las IES son los usuarios de primera línea que viven de cerca la gestión administrativa y académica de la institución, sin embargo, al ser temporal su relación, no son una fuente confiable para evaluarla. No obstante, el involucramiento de los estudiantes en calidad de consumidores o clientes y de maestros en calidad de trabajadores para el diseño de políticas de administración, fortalecerá internamente a la institución y permitirá su progreso.

\section{Conclusión}

Una excelente calidad en la educación y unos costes asequibles son los más frecuentes requerimientos que hace la sociedad a las IES, y, estas deben responder a ello proactiva, emprendedora y sosteniblemente.

Aspectos propios del territorio en donde se ubique la IES, afectan la gestión de esta. En ocasiones, se hace más complejo el desarrollo de su actividad y justamente éstos son retos que la gobernanza debe enfrentar y superar.

\section{Referencias}

Carreño Dueñas Dalia et al, (2018). Justicia constitucional para el posconflicto. Bogotá, Colombia: Universidad Santo Tomás

Carreño Dueñas Dalia et al (2019) El reino digital. Transformaciones y aplicaciones multidiciplinares. Bogotá, Colombia: Universidad Santo Tomás.

Carreño Dueñas Dalia et al (2020). De cómo construir el concepto emergente de la gobernanza Preprint (PDF Available). June 2020 DOI: 10.13140/RG.2.2.10241.68969

Carreño Dueñas Dalia et al (2020). Working Paper No.1 Gobernanza de las instituciones de educación superior Preprint (PDF Available) · June 2020. DOI:

10.13140/RG.2.2.26389.76005

Ganga, F., Quiroz, J., \& Fossatti, P. (2016). Análisis sincrónico de la gobernanza universitaria: Una mirada teórica a los años sesenta y setenta. Educação E Pesquisa, 43(2), 553-568. doi:10.1590/s1517-9702201608135289

Ganga,F., Nuñes,O.( 2018). Gobernanza de las organizaciones: Acercamiento conceptual a las instituciones de Educación Superior. Revista espacios,39(17), 9. 
Moya Vargas, Manuel Fernando. 2020. Análisis Semiótico de la Culpabilidad. En, Opúsculos de Neuroantropología Filosófica. La materia Prima del Derecho Penal y Disciplinario. Razón, emoción y el Dilema libre albedrío-determinismo de la conducta humana desde la perspectiva del inconsciente y la consciencia. Ediciones Nueva Jurídica. Bogotá Colombia

Moya Vargas, Manuel Fernando. 2018. "Fundamentos de la Semiótica Jurídica. Hacia una semiótica del derecho penal”, en Derecho Penal y Crimininología, vol. 38, n 105, 2018, pp. 179-206.

Ostos-Ortíz, Olga- Lucía y Aparicio- Gómez, Oscar- Yecid.( 2020). Bases Biológicas de la creatividad. Universidad Santo Tomás Working Paper No 197526

Ostos-Ortíz, Olga- Lucía y Aparicio- Gómez, Oscar- Yecid.( 2020). Bases científicas de la intuición. Universidad Santo Tomás Working Paper No 197527

Ostos-Ortíz, Olga -Lucía. ( 2020). Bases del Sistema Institucional de Investigación. Universidad Santo Tomás Working Paper No 197528

Torregrosa Jiménez, N. (2015). El artículo Científico que debemos escribir y como escribirlo. Verba Luris, (33), 11-14. https://doi.org/10.18041/0121-3474/verbaiuris.33.2

Torregrosa Jiménez, N. ( 2013). La producción de artículos científicos, Verba luris: Edición 30

Torregrosa,N.,\&Avila,J.J. (2020). Working Paper No.1.Gobernanza / Gobernanza de las instituciones de educación superior 